\title{
Solow (1956) as a Model of Cross-Country Growth Dynamics
}

\author{
Kieran McQuinn* and Karl Whelan ${ }^{\dagger}$ \\ Central Bank and Financial Services Authority of Ireland
}

October 9, 2006

\begin{abstract}
Despite the widespread popularity of the Solow growth model, much of the recent empirical work based on the classic framework misrepresents a crucial feature of the model. Namely, the growth rate of technological progress, assumed to be exogenous in the Solow model, is often identified as being constant across countries. This simplification of the behavior of technological progess runs counter to the evidence and has had a number of significant implications for the interpretation of the Solow model. One implication has been an overemphasis on the role of factor accumulation in explaining cross-country income differentials. In addition, the commonly-cited empirical result that the speed of conditional convergence is slower than predicted by the Solow model is a function of this inaccurate assumption about technology rather than due to a failure of the model itself.
\end{abstract}

\footnotetext{
*E-mail: kmcquinn@centralbank.ie

${ }^{\dagger}$ E-mail: karl.whelan@centralbank.ie. The views expressed in this paper are our own, and do not necessarily reflect the views of the Central Bank and Financial Services Authority of Ireland or the ESCB.
} 


\section{Introduction}

Robert Solow's 1956 model is widely used as a theoretical framework for understanding cross-country growth patterns. Worth noting, however, is that the 1956 paper contains no discussion at all of the model's predictions about patterns of growth across countries. In thinking about why this was the case, a useful starting point is the well-known result that output per worker can be expressed as a function of the level of technological efficiency and of the capital-output ratio. This decomposition fits well with the two principal predictions of the Solow model. First, the model predicts that the economy tends to converge towards a value for the capital-output ratio consistent with steady-state growth such that capital and output grow at the same rate. Second, the model predicts that the growth rate of this steady-state path is determined only by technological efficiency, which is taken to be exogenous.

These considerations help to make it clearer why Solow's article was silent on crosscountry growth patterns. While it does make predictions related to conditional convergence (the tendency of the capital-output ratio to converge to its steady-state value), one can only get predictions from the Solow model about the behavior of output per worker by making assumptions about technological efficiency, which the model takes to be exogenous. In the modern empirical growth literature, starting with Mankiw, Romer, and Weil (1992, henceforth MRW), the assumption of exogenous technology has been interpreted as a statement that technology or total factor productivity (TFP) grows at the same exogenous rate in all countries. As a result, any variations in levels of TFP are due to fixed country-specific factors.

In this paper, we argue that this modern approach to implementing the Solow modelwedding the model to an assumption of constant TFP growth across countries - has had a number of unsatisfactory implications. The first is that it has promoted a representation of the Solow model that is at odds with what could be viewed as the model's fundamental message. While the model takes technological progress to be exogenous, there is little reason to characterize this as implying that TFP grows at the same rate everywhere. Indeed, Solow has often rejected this characterization of his model. However, if it is assumed that TFP grows at the same rate everywhere, then all empirical differences in growth rates of output per worker must be assigned to variations in capital intensity. This idea runs counter to the fundamental message of the Solow model that technological progress is the ultimate determinant of growth in output per worker. 
The second problem with this approach is that it leads to an inaccurate view of the facts relating to cross-country growth patterns. The MRW paper has been very influential and its identifying assumption of constant technology growth across all countries has been adopted by a large number of empirical growth studies. ${ }^{1}$ However, as has previously been stressed by Klenow and Rodriguez-Clare (1997) and by Easterly and Levine (2001), the data strongly point to substantial differences across countries in TFP growth rates, with these differences accounting for almost all of the variance across countries in growth of output per worker.

The final problem with this approach has been that a number of studies have argued that the Solow model fails to fit the data along certain important dimensions. We believe, however, that these rejections have often reflected the unsatisfactory nature of the MRW assumption about technology, rather than failures of the model itself. In particular, we highlight the widely-cited and influential "stylized fact" that the speed of conditional convergence is substantially slower than predicted by the Solow model. We argue that, correctly estimated, conditional convergence speeds are very similar to, but slightly higher than, the values predicted by the model.

The rest of our paper is structured as follows. Section 2 briefly reviews the Solow model's predictions for long-run and short-run growth dynamics. While these predictions are relatively well known, we repeat them here because we want to emphasize a few points in relation to the model's dynamics that tend to be overlooked in the literature. In particular, we highlight how the process of conditional convergence takes place through the adjustment of the capital-output ratio. Section 3 discusses tests of the model's long-run steady-state predictions. Section 4 discusses the standard identifying assumption of common technology growth, and illustrates its empirical shortcomings. Section 5 presents some results on conditional convergence speeds, emphasizing how these speeds can be estimated from the behavior of the capital-output ratio without making strong assumptions about the behavior of technology. We also discuss how this approach solves a number of the econometric problems that have plagued this literature in the past. Section 6 concludes.

\footnotetext{
${ }^{1}$ The popularity of Mankiw, Romer, and Weil's contribution can be judged from the fact that it is the the commonly-cited work by papers included in the REPEC collection of online papers in economics. See http://ideas.repec.org/top/top.item.nbcites.html
} 


\section{Long and Shorter-Run Dynamics in the Solow Model}

It is well known that the Solow model makes strong predictions about long-run steadystate growth paths. However, the model's out-of-steady-state dynamics seem to be less well understood, and this has lead to some confusion about its predictions for cross-country growth patterns. Here, we outline a compact presentation of the model's dynamicspresented previously in Brad DeLong's (2003) macroeconomics textbook - which allows for a simple integration of the model's long and shorter-run predictions.

The Solow model has two key elements. The first is the assumption that the economy can be characterized with a neoclassical aggregate production function with exogenous technological change. For concreteness, we follow most of the recent literature and represent the model with a Cobb-Douglas aggregate production function

$$
Y_{t}=K_{t}^{\alpha}\left(A_{t} L_{t}\right)^{1-\alpha},
$$

where $Y_{t}$ is aggregate output, $K_{t}$ is capital, $L_{t}$ is the number of workers, and $A_{t}$ is exogenous labor-augmenting technological change. ${ }^{2}$ The second element is the assumption that the capital stock accumulates according to

$$
\dot{K}_{t}=s Y_{t}-\delta K_{t},
$$

where $s$ is the investment share of output, also assumed to be exogenous.

The properties of this model can perhaps be better understood by using a reformulated version of the production function, derived as follows. Defining the capital-output ratio as

$$
X_{t}=\frac{K_{t}}{Y_{t}}
$$

output per worker can be expressed as

$$
\frac{Y_{t}}{L_{t}}=A_{t} X_{t}^{\frac{\alpha}{1-\alpha}}
$$

This is the decomposition of output per worker into technology and capital-output components referred to in the introduction. ${ }^{3}$ If we denote the growth rates of technology and

\footnotetext{
${ }^{2}$ It is well known, of course, that Solow's results about long-run steady-state growth apply for any production function with diminishing marginal returns to capital. However, we wish to emphasize the dynamics of the model, and these are usually derived by obtaining a first-order log-linearization, which is equivalent to assuming a Cobb-Douglas production function.

${ }^{3}$ While we have derived this representation from a Cobb-Douglas production function, a relationship expressing output per worker as a function of technology and the capital-output ratio can be derived for any constant returns to scale production function featuring labor-augmenting technological change. See McQuinn and Whelan (2006).
} 
the number of workers as $g$ and $n$ respectively, then one can easily combine the separate dynamics for output and capital to obtain the dynamics of the capital-output ratio as

$$
\dot{X}_{t}=\lambda\left(X^{*}-X_{t}\right) \text {, }
$$

where

$$
\lambda=(1-\alpha)(g+n+\delta) .
$$

and

$$
X^{*}=\frac{s}{g+n+\delta} .
$$

These results provide a simple analytical formulation of the Solow model's long-run predictions as well as its shorter-run dynamics. The capital-output ratio tends to converge over time at rate $\lambda$ to an equilibrium level that is a function of the investment rate $s$, the growth rate of technology $g$, the growth in the number of workers $n$ and the depreciation rate $\delta$. Once the economy has reached this value for the capital-output ratio, output per worker then grows at the rate $g$ given by the rate of labor-augmenting technological progress.

That the equilibrium level of the capital-output ratio is independent of the level of $A_{t}$ is a key advantage of equation (4) as a decomposition of the determinants of growth. In contrast, the more familiar decomposition of output per worker into technology and capital-per-worker terms suffers from the disadvantage that capital-per-worker depends positively on $A_{t}$ in the long-run, making it more difficult to disentangle the long-run effects of technology and non-technology factors.

To understand the link between capital-output dynamics and output per worker dynamics, it is useful to note that the $\log$ of the capital-output ratio can also be approximated as displaying a simple convergence property. In other words, letting $x_{t}$ be the log of this ratio, then

$$
\dot{x}_{t}=\frac{\dot{X}_{t}}{X_{t}}=\lambda\left(\frac{X^{*}-X_{t}}{X_{t}}\right) \approx \lambda\left(x^{*}-x_{t}\right)
$$

This result allows for a simple characterization of the dynamics of output per worker. Again letting lower-case letters represent logged variables, we can take logs of equation (4) to get

$$
y_{t}=a_{t}+\frac{\alpha}{1-\alpha} x_{t} .
$$

The steady-state path for output per worker is defined as the level of output per worker consistent with the capital-output ratio being at its equilibrium level:

$$
y_{t}^{*}=a_{t}+\frac{\alpha}{1-\alpha} x^{*} .
$$


Using equation (8), output per worker dynamics can then be expressed as

$$
\dot{y}_{t}=g+\lambda\left(y_{t}^{*}-y_{t}\right) .
$$

Thus, the convergence speed, $\lambda$, of the capital-output ratio is also the so-called conditional convergence speed of output-per-worker. In other words, this is the speed at which output per worker closes the gap towards its steady-state level. Note, however, that the output growth equation has two components to it: Growth is determined by technological progress as well as the gap between $y_{t}$ and $y_{t}^{*}$. In contrast, movements in the capital-output ratio are determined only by the gap between output and its steady-state level.

\section{Solow and Cross-Country Output Levels}

It is worth emphasizing that to obtain any predictions from the Solow model about patterns of output across countries, it is necessary to add an assumption about how technology behaves in each country. However, if one makes assumptions about technology that are inaccurate, this can lead to essentially spurious "rejections" of the Solow model itself. In this paper, we will discuss two examples of how this problem has occurred in the empirical growth literature.

Our first, and simplest, example of this problem concerns the Solow model's predictions regarding the cross-country relationship between output per worker on the one hand and investment shares and population growth on the other. MRW's paper argued that the Solow model underestimated the long-run empirical relationship between output per worker and these variables. Their analysis started from the assumption that deviations of economies from their steady-states should be random, so the model's long-run predictions could be assessed by comparing levels of output per worker across countries with the steady-state levels predicted by the model. If this is combined with the assumption that the level of $A_{t}$ is uncorrelated with the investment share and rate of population growth, then the long-run predictions of the Solow model can be assessed with a regression of the form

$$
\log \left(\frac{Y_{i}}{L_{i}}\right)=a+\frac{\alpha}{1-\alpha}\left(\log \left(s_{i}\right)-\log \left(n_{i}+g+\delta\right)\right)+\epsilon_{i} .
$$

MRW estimated this equation measuring $s_{i}$ and $n_{i}$ by their sample averages and setting $g+$ $\delta=0.05 .{ }^{4}$ The implied value of $\alpha$ obtained from this regression by MRW was $0.60 .{ }^{5}$ Because

\footnotetext{
${ }^{4}$ This equation is obtained by taking logs of equation (4) and then assuming the economy is approximately at its steady-state so that equation (7) approximately holds.

${ }^{5}$ Similarly, when we run this regression using the year 2000 for the left-hand-side and sample averages
} 
estimated capital shares of income are so much lower than this value, MRW concluded that the evidence implied an elasticity of output with respect to investment and population growth that was far higher than implied by the basic Solow model.

An important qualification to this result, however, is that it relies on the identifying assumption that the level of a country's TFP is uncorrelated with its investment share and rate of population growth. How reasonable is this assumption?

One way to answer this question is to use information on capital shares to calibrate $\alpha$ and then calculate a series for $A_{t}$ for each country, in the manner of the "levels accounting" exercise of Hall and Jones (1997). This approach uses data on output, capital, and workers to back out a series for $A_{t}$ from equation (1). We carried out these calculations using data from version 6.1 of the Penn World Tables, as documented by Heston, Summers, and Aten (2002) and using the standard value of $\alpha=\frac{1}{3} .{ }^{6}$ We used data for the ninety-six countries listed in Appendix A over the period 1960-2000. The resulting series for cross-country TFP levels could then be checked for correlations with investment shares and population growth.

Figures 1 and 2 show that our estimated TFP levels are positively correlated with investment shares and negatively correlated with population growth rates. These correlations are not sensitive to particular assumptions underlying the calculations. For instance, similar results are obtained using values of $\alpha$ ranging from 0.25 to 0.45 . In addition, replacing the value of $\alpha=\frac{1}{3}$ with the labor shares calculated by Bernanke and Gurkaynak (2002) implies almost no change in the estimated correlations. Variations in assumptions underlying the capital stock calculations also have essentially no impact on the results. So, we take from these results that these correlations most likely reflect a true underlying pattern. For instance, the correlation could be driven by the common influence that institutions have on productive efficiency as well as incentives to invest and factors relating to population growth.

These calculations show that the level of TFP is systematically positively correlated with the right-hand-side variable in the regression described by equation (12), so the regression will produce upward-biased estimates of $\alpha{ }^{7}$ This suggests that what is actually

over 1960-2000, we obtain a value of $\alpha$ of 0.57 .

${ }^{6}$ Details behind our calculations of the capital stocks are described in an appendix.

${ }^{7}$ Monte Carlo exercises simulating the steady-state of the Solow model under the assumption of $\alpha=\frac{1}{3}$ and a covariance matrix for TFP, investment shares, and population growth rates that are calibrated to match those in the data confirm that the estimated coefficients in this regression are perfectly consistent with a capital share of one-third. 
being rejected when equation (12) is estimated is a specific identifying assumption about technology - that it is uncorrelated with investment shares or population growth - rather than the Solow model itself.

\section{Cross-Country TFP Patterns}

Our second example of how inaccurate assumptions about cross-country technology patterns has lead to spurious rejections of the Solow model relates to the speed at which economies converge towards their steady-state growth paths. The empirical literature on estimating this speed has used regressions for the growth rate of output per worker. Again, in this case, it is clear that obtaining predictions from the Solow model for the behaviour of output growth requires an assumption about how technological progress behaves in each country. The canonical approach in this literature has been to follow Mankiw, Romer, and Weil (1992) and assume that the growth rate of technological progress is constant across countries. In this section, we discuss this assumption and assess its empirical accuracy. In the next section, we discuss the implications of this assumption for empirical estimates of the speed of convergence.

\subsection{What Does Solow Actually Say?}

The predictions from MRW's empirical model have become so well known that, to many, they are considered the same thing as the predictions of the Solow model. However, it should be noted that this assumption runs counter to the fundamental message of the model. With this assumption in hand, all differences in growth rates across countries must reflect outof-steady-state dynamics, which in turn are due to variations in the capital-output ratio. Mankiw (1995) describes this point as follows:

A ... goal is to explain the variation that we observe in growth in different countries and in different times. For this purpose, the neoclassical model's assumption of constant, exogenous technological change need not be a problem. Even with this assumption, the model .... predicts that different countries will have different rates of growth, depending on each country's initial deviation from its own steady-state. Thus, the assumption of constant exogenous technological change does not preclude addressing many of the central issues of growth theory. 
Given its limiting implications, it is hardly surprising that Robert Solow himself has explicitly rejected the model of technology outlined by MRW on a number of occasions. For instance, Solow (2001, page 284), when commenting on his own experience teaching growth theory, notes that starting from the idea of a production function:

it is natural to think of $A(t)$ in purely technological terms. That may be how the habit was established of supposing that the shape of the production function and the path of $A(t)$ were common across countries. But soon questions would arise; if they didn't, I would raise them myself.

MRW argue for the assumption of constant growth in technology across countries on the grounds that " $g$ reflects primarily the advancement of knowledge, which is not countryspecific." However, Solow has also explicitly rejected this idea. For instance, Solow (2000, page 103) states

The usual presumption seems to be that technology is universal, if only because handbooks of science and engineering are easily and promptly available everywhere. But that seems superficial to me. Abstract technological knowledge by itself butters no parsnips. For two countries to have effectively the same technology is very much a matter of workers' skills and attitudes toward work, managerial and administrative habits, interpersonal attitudes, social norms and institutions, and no doubt many other hard and soft characteristics of the economic and social environment.

The assumption of identical growth rates still allows for differences in the levels of $A_{t}$ across countries, which MRW have explained as reflecting "not just technology but resource endowments, climate, institutions, and so on." There seems little reason, however, to restrict the set of factors that determine differences in TFP levels to those that are constant over time. Indeed, the very existence of large variations in TFP levels is an indication that there have been differences in the past in TFP growth rates, which raises the question of why such differences could not be seen again.

\subsection{What Does The Evidence Say?}

While the "levels accounting" calculations underlying Figures 1 and 2 are imperfect, they can help to assess how accurate the assumption of common growth in technology across 
countries. Our calculations based on $\alpha=\frac{1}{3}$ show that there are substantial variations in TFP growth across countries. For instance, over the period 1960-2000, TFP growth in the bottom 10th percentile averaged -2.4 percent per year, while in the top 10th percentile it averaged 4.1 percent per year.

On their own, however, these figures are not evidence against the usefulness of MRW's identifying assumption, which may still be a convenient simplification. For instance, if most of the variance in growth rates across countries was due to variations in capitaloutput growth, then the assumption would not be misleading. However, Figures 3 and 4 show that the opposite is the case. Figure 3 shows that variations in TFP growth are the dominant source of variation across countries in their growth rates of output per worker, with a positive correlation between these two series of 0.79. In contrast, Figure 4 shows that there is a slight negative correlation between the growth rates of the capital-output ratio and output-per-worker.

These calculations should hardly be too surprising to students of the Solow model. The model's fundamental result is that, over the long run, growth in output per worker is determined by technological progress. The correlation evident in Figure 3 simply confirms this central prediction. ${ }^{8}$ The model also predicts that the capital-output ratio should adjust over time towards its equilibrium value. However, Figure 4 shows that this has not been a dominant source of growth over long periods. In other words, while Mankiw's argument cited above that a model with constant technological change across countries could, in principle, explain growth differences across countries, the data reject this idea in practise.

It is important to stress that these results are not dependent on particular assumptions underlying the calculations. Again, essentially the same results are obtained using values of $\alpha$ ranging from 0.25 to 0.45 or using the Bernanke-Gurkaynak values. Also, the incorporation of estimates of the stock of human capital as an additional input also produces essentially the same findings: Similar calculations to these were reported by Klenow and Rodriguez-Clare (1997) who included proxies for human capital.

\footnotetext{
${ }^{8}$ In this sense, we agree strongly with Erich Gundlach (2005) that the MRW specification of technology contradicts the fundamental insight of the Solow model. We would disagree, however, with Gundlach's characterization of the Solow model as assuming that the capital-output ratio is constant. Adjustment of the capital-output ratio is the mechanism by which the model adjusts to its steady-state path. That such a stable adjustment process exists was one of the key contributions of Solow's analysis.
} 


\section{Conditional Convergence}

One of the principal "stylized facts" in the modern empirical growth literature is that the speed of conditional convergence is lower than predicted by the Solow model. This result was first presented by Mankiw, Romer, and Weil (1992) but was also reported in an another influential study by Barro and Sala-i-Martin (1992). Both studies suggested convergence speeds on the order of about two percent per year, which is slower than would be obtained from filling in reasonable parameter values into equation (6). Since these studies, there has been a huge number of empirical "growth regression" studies that have reported a wide range of estimates for the convergence speed; the two percent figure, however, remains widely cited in textbooks and popular discussions.

In this section, we present new estimates of the speed of conditional convergence. Our estimates are close to those predicted by the Solow model. The difference between our approach and those in the previous literature is that our estimates do not rely on ad hoc and inaccurate assumptions about the rate of technological progress across countries. After introducing our approach and presenting our estimates, we provide a review of the advantages of this method. In particular, we describe how our approach solves a number of crucial econometric problems that have afflicted this literature.

\subsection{Estimates Based on the Capital-Output Ratio}

Our empirical approach relies on the result, presented in Section 2, that the process of conditional convergence operates through the adjustment of the capital-output ratio towards its equilibrium value. Thus, we directly estimate the speed of adjustment from the capitaloutput ratio rather than estimate a model for the dynamics of output per worker. Section 2 derived a continuous-time adjustment mechanism for the capital-output ratio. This implies the following relationship that can be estimated using discrete time data based on $r$-period intervals: ${ }^{9}$

$$
x_{i t}=\left(1-e^{-\lambda r}\right) x_{i t}^{*}+e^{-\lambda r} x_{i, t-r}+v_{i t} .
$$

We estimate the parameter $\lambda$ by applying OLS estimation to this equation. Our empirical implementation of this equation follows the convention of most of the empirical growth

\footnotetext{
${ }^{9}$ This result comes from the fact that equation (8) has an analytical solution of the form

$$
x_{t}=e^{-\lambda t} x_{0}+\left(1-e^{\lambda t}\right) x^{*}
$$
}


literature and uses data drawn from five-year intervals. We allow the "target" capital-output ratio to change in line with the average values of the investment rate and population growth rate over each five-year period. In addition, the value of $g$ used to define each country's target capital-output ratio was based on the average growth rate of $A_{i t}$ for that country over 1960-2000. This means that our method does not impose any restrictive assumptions about technology growth occurring at a common rate across countries.

Implementing this method requires the construction of data on capital and thus requires an assumption about the depreciation rate; this also applies to the MRW method which assumes $g+\delta=0.05$. The convergence rate predicted by the Solow model also depends on the assumed depreciation rate. For this reason, Table 1 reports our estimates of $\lambda$ for three different depreciation rates ranging from four to six percent. The table also reports the average convergence rate predicted by the Solow model for each of these depreciation rates, using the sample average values across countries for $g$ and $n$.

The results in Table 1 show that the convergence rate of the capital-output ratio-and hence the conditional convergence speed for output per worker - is estimated in each case to be similar to, but slightly higher than predicted by the Solow model. Table 2 reports results for two other samples of countries commonly used in empirical growth studies: An Intermediate sample of 80 countries based on the exclusion of countries that received a grade D for data quality, as well as countries with populations of below one million in 1960, and an OECD sample of 23 countries. Again, the results suggest convergence speeds close to those implied by the Solow model. In all cases, the estimated convergence speeds are in the range of six to seven percent per year, which is well above the widely-cited two percent stylized fact.

These results are robust to a wide range of alternative estimation procedures. For instance, McQuinn and Whelan (2006) report that one can reject the presence of countryspecific fixed-effects in these regressions, but that the standard within groups fixed effects estimator gives almost identical results to those reported here. Similar estimates are also obtained from the average convergence speed obtained from estimating 96 country-specific regressions, from using one-year instead of five-year intervals, and from regressions that separately estimate the coefficients on the lagged capital-output ratio, the investment share and the population growth variable. 


\subsection{Comparisons of the Two Approaches}

We believe that our approach of focusing on the dynamics of the capital-output ratio provides a simple and robust way of estimating the speed at which economies converge to their steady-state path. However, the traditional approach to estimating this convergence speed has focused instead on estimating dynamic equations for output per worker. To understand the relationship between our approach and the traditional approach, note that from equation (9) our estimating equation can be re-expressed in terms of output per worker as

$$
y_{i t}=a_{i t}-e^{-\lambda r} a_{i, t-r}+\frac{\alpha\left(1-e^{-\lambda r}\right)}{1-\alpha} x_{i t}^{*}+e^{-\lambda r} y_{i, t-r}+v_{i t} .
$$

If one used data on the level of technology at times $t$ and $t-r$, estimation of this equation would produce identical results to our method. However, the traditional literature has not gone down this route. Instead, it has used MRW's restrictive approach of assuming that all differences in technology levels across countries are due to fixed country-specific factors. In this case, the output growth equation can be written as

$$
y_{i t}=\gamma_{i}+\omega_{t}+\frac{\alpha\left(1-e^{-\lambda r}\right)}{1-\alpha} x_{i t}^{*}+e^{-\lambda r} y_{i, t-r}+v_{i t} .
$$

Versions of this equation have been widely estimated in the growth literature: In addition to the 1992 MRW and Barro and Sala-i-Martin papers, which used single cross-sections of data, there have been a significant number of papers that have followed Islam (1995) and Caselli, Esquivel, and Lefort (1996) in using a panel data approach.

\subsection{Advantages of the Capital-Output Approach}

In comparing our approach based on capital-output dynamics with the traditional convergence regression, we think it is useful to separate two distinct points. The first point is that our approach has some important econometric advantages even when the identifying assumption of common technology growth across countries is correct, because it does not require estimation of country-specific fixed effects. The second point is that the evidence reported above in Section 4 clearly shows that this identifying assumption of common technology growth is incorrect, and this implies a set of new econometric problems not previously discussed in the growth literature. We will take these two points in turn.

Problems Related to Fixed Effects: The presence of country-specific fixed effects (the $\gamma_{i}$ terms) is well-known to imply a number of econometric problems relating to estimation 
of dynamic panel models. ${ }^{10}$ While much of the literature since MRW's paper has devoted itself to increasingly-sophisticated attempts to deal with these problems, we think it is fair to say that there is no agreement on the best estimation technique for this model:

- The approach of MRW and Barro and Sala-i-Martin (1992) was to run a pure crosssection regression with one observation for each country. Because it is impossible to estimate country-specific effects in this case, these terms get absorbed into the error term. These effects are by definition positively correlated with the lagged output term, $y_{i, t-r}$, so this approach leads to an upward bias on this coefficient and thus a downward bias in the implied convergence speed. Hence, despite being widely-cited, the low estimated convergence speeds obtained from these studies should be somewhat discounted.

- Panel techniques such as the within-groups estimator acknowledge the existence of the fixed effect but do not eliminate the biases associated with them. Effectively, this technique transforms the model by subtracting off country-specific means. However, Nickell (1981) has documented that this transformation induces a new correlation between the transformed error term and the lagged endogenous variable, so estimates from this method are upward-biased. So, while Islam (1995) reported estimated convergence speeds that were higher than those in the cross-sectional studies, these estimates should also be discounted somewhat.

- First-differencing the model eliminates the fixed effect from the specification but this transformation induces its own problems: The transformed error term is negatively correlated with the transformed lagged dependent variable, so OLS estimation gives upward-biased convergence speeds. Thus, Caselli, Esquivel, and Lefort (1996) and others have estimated the model using GMM. However, valid instruments for this problem can be difficult to obtain and many of these studies that have employed this technique appear to suffer from serious weak instrument problems. ${ }^{11}$

Given the seriousness of these econometric problems, we view the fact that the capitaloutput dynamic equation does not contain country-specific fixed effects (and the presence of these effects being rejected empirically) as a major methodological advantage of this approach.

\footnotetext{
${ }^{10}$ Bond (2002) provides a useful detailed discussion of these econometric problems.

${ }^{11}$ See Bond, Hoeffler, and Temple (2001)
} 
Problems Related to the Technology Assumption: The evidence detailed in Section 4 firmly points against the hypothesis that technological efficiency tends to grow at a common rate across countries at all times. This type of evidence has been presented before by Klenow and Rodriguez-Clare (1997) and Easterly and Levine (2001). But, as of yet, there has been little discussion in the empirical growth literature of the implications of these findings for growth regressions. As our discussion above illustrates, once technology growth deviates from the assumption of common growth across countries at all times then one cannot use the "time-and-country-effects" specification to capture the role of technology. This necessarily implies that the growth regressions are mis-specified and thus may lead to bias.

The exact nature of this bias will depend on the specific processes that determine TFP growth. However, calculations reported in McQuinn and Whelan (2006) suggest to us that realistic processes for cross-country technology are consistent with the existence of substantial mis-specification biases in traditional growth regressions. For instance, one simple process for technology that allows for realistic deviations from the traditional approach is of the form

$$
\Delta a_{i t}=g_{t}+\epsilon_{i t}
$$

This approach maintains the Mankiw-Romer-Weil idea of a common world technology trend representing advancement of knowledge, while also allowing for the country-specific shocks required to explain the actual evidence on TFP growth. While this specification requires a relatively small change from the standard assumption about technology (which implies $\left.\Delta a_{i t}=g_{t}\right)$ it turns out to have very important implications for output per worker regressions.

Specifically, one can show that with a technology process of this form, within-groups estimation of equation (15) produces estimated convergence speeds that are biased downwards. This contrasts with the traditional assumption that such regressions produce estimated convergence speeds that are biased upwards. These considerations help to explain why our estimated convergence speeds are higher than the four to five percent figures reported by Islam (1995) using an estimator that has been thought to be upward biased.

Before leaving this issue, we should note that there is one prominent contribution to the empirical growth literature that has noted some of the issues raised by differences in growth rates of technology across countries. Lee, Pesaran, and Smith $(1997,1998)$ have dealt with this issue by replacing the common time-effect of the standard output per worker 
framework with country-specific time trends. However, there are a number of potential drawbacks to this approach. First, the variation in technology patterns across countries may be stochastic, so that a country-specific deterministic trend still fails to adequately capture the behavior of technology. Second, as Andrews (1993) as shown, OLS estimation of $\mathrm{AR}(1)$ models with time trends produce substantially downward biased estimates of the coefficient on the lagged dependent variable in finite samples. This corresponds in our case to upward-biased estimates of convergence speeds. Indeed, Lee, Pesaran and Smith report an average convergence speed of about 30 percent per year when estimating separate country-specific regressions of this form. These estimates are consistent with a true convergence speed of about six to seven percent, as reported in our estimates, once the finite-sample upward bias documented by Andews is taken into account.

\section{Conclusion}

"Most of the change we think we see in life is due to truths being in and out of favour"

In quoting Robert Frost in his Nobel prize-winning lecture, Robert Solow made a subtle, but telling case for the enduring strength and challenge of his 1950s growth contributions. It can be argued that much of the subsequent criticisms of the Solow model lie not in any significant weaknesses of his landmark growth framework, but more in the general inability of the economics profession to subsequently advance the theory from its initial premises.

That the model views technological progress as exogenous and unexplained has meant that it is hard to use it to obtain predictions about patterns of growth across countries. However, the combination in the early 1990s of the emergence of the Summers-Heston dataset and a renewed interest in growth theory meant that the profession was hungry for growth regressions. Thus, Mankiw, Romer and Weil's version of the Solow model has come to represent, for many, the empirical predictions of the model itself. So, a model that stresses the fundamental role of technology rather than accumulation in determining growth has come to be viewed as a model in which it is variations in accumulation that determine cross-country growth patterns.

The evidence points to systematic differences across countries in TFP growth, with these being the fundamental source of differences in growth rates of output per worker. We think these facts favor the fundamental message of the Solow model but undermine the empirical literature that has implemented the model based on the assumption of constant 
technology growth across countries. In particular, in contrast to the bulk of this empirical literature, we have presented evidence that the empirical process of conditional convergence is very close to that predicted by the Solow model. Thus, to the extent that the model makes predictions about cross-country growth dynamics, the evidence suggests it actually fits well.

The other way in which the profession's view of the Solow model has changed over time is in its assessment of the model's treatment of technology. Without a specific theory of how technological progress comes about, the Solow model is sometimes seen as a growth theory that is silent on the ultimate determinant of growth. While this is true, we think that it is hard even today to question the wisdom of Solow's modelling assumption. Despite the enormous literature devoted to endogenizing technological change in the 1980s and 1990s, there is still no agreed model of what determines technological efficiency across countries. Indeed, the profession has begun moving away from the narrow innovation-centric focus of the endogenous growth models. With the work of Hall and Jones (1997), Acemoglu, Johnson, and Robinson (2001) and others, recent research has begun to focus more on detailed examinations of the effects on long-run growth of less mechanical factors such as institutions, which Solow has always viewed as likely to be important determinants of cross-country growth patterns.

\section{References}

[1] Acemoglu, Daron, Simon Johnson, and James Robinson (2001). "The Colonial Origins of Comparative Development: An Empirical Investigation," American Economic Review, 91, 1369-1401.

[2] Andrews, Donald (1993). "Exactly Median-Unbiased Estimation of First-Order Autoregressive/Unit Root Models," Econometrica, 61, 139-165.

[3] Barro, Robert and Xavier Sala-i-Martin (1992). "Convergence," Journal of Political Economy, 100, 223-251.

[4] Bernanke, Ben and Refet Gurkaynak (2002). "Is Growth Exogenous? Taking Mankiw, Romer and Weil Seriously," NBER Macroeconomics Annual, pp. 11-57.

[5] Bond, Stephen, Anke Hoeffler, and Jonathan Temple (2001). GMM Estimation of Empirical Growth Models, CEPR Discussion Paper No. 3048. 
[6] Bond, Stephen (2002). Dynamic Panel Data Models: A Guide to Micro Data Methods and Practice, UCL Working paper CWP09/02.

[7] Caselli, Francesco, Gerardo Esquivel, and Fernando Lefort (1996). "Reopening the Convergence Debate: A New Look at Cross-Country Growth Empirics," Journal of Economic Growth, 1, 363-389.

[8] DeLong, J. Bradford (2003). Macroeconomics, McGraw-Hill.

[9] Easterly, William and Ross Levine (2001). "It's Not Factor Accumulation: Stylized Facts and Growth Models" World Bank Economic Review, 15, 177-219.

[10] Gundlach, Erich (2005). The Solow Model in the Empirics of Cross-Country Growth, working paper, Kiel Instiute for World Economics.

[11] Hall, Robert and Charles I. Jones (1997). Why Do Some Countries Produce so Much More per Worker than Others?, Quarterly Journal of Economics, 114, 83-116.

[12] Heston, Alan, Robert Summers, and Bettina Aten (2002). Penn World Table Version 6.1, Center for International Comparisons at the University of Pennsylvania.

[13] Islam, Nazrul (1995). "Growth Empirics: A Panel Data Approach," Quarterly Journal of Economics, 110, 1127-1170.

[14] Klenow, Peter and Andres Rodriguez-Clare (1997). "The Neoclassical Revival in Growth Economics: Has it Gone Too Far?" NBER Macroeconomics Annual.

[15] Lee, Kevin, M. Hashem Pesaran, and Ron Smith (1997). "Growth and Convergence in a Multi-Country Empirical Stochastic Solow Model," Journal of Applied Econometrics, $12,357-392$.

[16] Lee, Kevin, M. Hashem Pesaran, and Ron Smith (1998). "Growth Empirics: A Panel Data Approach — A Comment," Quarterly Journal of Economics, 113, 319-323.

[17] Mankiw, N. Gregory, David Romer, and David Weil (1992). "A Contribution to the Empirics of Economic Growth," Quarterly Journal of Economics, 107, 407-437.

[18] Mankiw, N. Gregory (1995). "The Growth of Nations," Brookings Papers on Economic Activity, Volume 1, 275-326. 
[19] McQuinn, Kieran and Karl Whelan (2006). "Conditional Convergence Revisited: Taking Solow Very Seriously," Central Bank of Ireland Working paper.

[20] Nickell, Stephen (1981). "Biases in Dynamic Models with Fixed Effects," Econometrica, 49, 1417-1426.

[21] Solow, Robert (1956). "A Contribution to the Theory of Economic Growth," Quarterly Journal of Economics, 70, 65-94.

[22] Solow, Robert (1988). "Growth Theory and After," American Economic Review, 78, 307-317.

[23] Solow, Robert (2000). Perspectives on Growth Theory, Second Edition, Oxford University Press.

[24] Solow, Robert (2001). "Applying Growth Theory Across Countries," World Bank Economic Review, 15, 283-288. 


\section{A Definitions of Data Sets}

All data come from the Heston, Summers, and Aten (2002) Penn World Tables, Version 6.1. The following list defines the three data sets used in our regressions.

\begin{tabular}{|c|c|c|c|}
\hline Argentina & Ecuador & Jordan & Philippines \\
\hline Australia $^{O}$ & Egypt & Kenya & Portugal $^{O}$ \\
\hline Austria $^{O}$ & El Salvador & Korea $^{O}$ & Romania \\
\hline Bangladesh & Ethiopia & Lesotho $^{N I}$ & Rwanda \\
\hline Barbados $^{N I}$ & Finland ${ }^{O}$ & $\operatorname{Luxembourg}^{N I}$ & Senegal \\
\hline Belgium $^{O}$ & France $^{O}$ & Madagascar & Seychelles $^{N I}$ \\
\hline Benin & Gabon $^{N I}$ & Malawi & South Africa \\
\hline Bolivia & Gambia $^{N I}$ & Malaysia & Spain $^{O}$ \\
\hline Brazil & Ghana & Mali & Sri Lanka \\
\hline Burkina Faso & Greece $^{O}$ & Mauritius $^{N I}$ & Sweden $^{O}$ \\
\hline Burundi & Guatemala & Mexico $^{O}$ & Switzerland $^{O}$ \\
\hline Cameroon & Guinea & Morocco & Syria \\
\hline Canada $^{O}$ & Guinea-Bissau $^{N I}$ & Mozambique $^{N I}$ & Tanzania \\
\hline Cape Verde ${ }^{N I}$ & Honduras & Nepal & Thailand \\
\hline $\operatorname{Chad}^{N I}$ & Hong Kong & Netherlands ${ }^{O}$ & $\operatorname{Togo}^{N I}$ \\
\hline Chile & Iceland $^{N I}$ & New Zealand $O$ & Trinidad and Tobago \\
\hline China & India & Nicaragua & Turkey $^{O}$ \\
\hline Colombia & Indonesia & Niger $^{N I}$ & Uganda $^{N I}$ \\
\hline Comoros $^{N I}$ & Iran & Nigeria & United Kingdom $^{O}$ \\
\hline Congo & Ireland ${ }^{O}$ & Norway $^{O}$ & Uruguay \\
\hline Costa Rica & Israel & Pakistan & $\mathrm{USA}^{O}$ \\
\hline Cote D'Ivoire & Italy $^{O}$ & Panama & Venezuela \\
\hline Denmark $^{O}$ & Jamaica & Paraguay & Zambia \\
\hline Dominican Republic & $\operatorname{Japan}^{O}$ & Peru & Zimbabwe \\
\hline
\end{tabular}

Note: $N I$ means a country is not a member of the Intermediate sub-sample, while $O$ means a country is a member of the OECD sub-sample. 


\section{B Capital Stock Calculations}

Given an assumed depreciation rate, we can construct time series for capital stocks once we have an initial value for each stock. While initial capital stocks cannot be observed, one can make an informed guess based on the observation that the ratio of investment to capital is given by

$$
\frac{I_{t}}{K_{t-1}}=\frac{\Delta K_{t}}{K_{t-1}}+\delta
$$

and thus,

$$
K_{t-1}=\frac{I_{t}}{\frac{\Delta K_{t}}{K_{t-1}}+\delta}
$$

Our approach has been to construct an initial capital stock for 1960 for each country in our sample according to this formula, using the average growth rate of investment over the previous decade as our proxy for the growth rate of the capital stock. This initial assumption appears to be quite accurate. For instance, when we apply this method to construct a proxy for the year 2000 stock, the resulting estimates have a correlation of 0.99 with the figures based on the 1960 initial conditions assumption, even though this latter series is almost completely based on data rather than initial assumptions. ${ }^{12}$

For the depreciation rate, we assume a rate of six per cent. Clearly, various types of capital depreciate at very different rates: Structures tend to depreciate at rates below two percent per year, while equipment tends to depreciate at rates above ten percent. An equally-weighted average of a two percent structures depreciation rate and a ten percent equipment depreciation rate points to an overall depreciation rate of six percent. McQuinn and Whelan (2006) provide a detailed discussion on this point.

\footnotetext{
${ }^{12}$ For instance, for our preferred depreciation rate of six percent, the starting 1960 value of the capital stock receives a weight of $(1-0.06)^{40}=0.084$ in the 2000 stock.
} 
Table 1: General Sample Convergence Estimates $\left(\lambda^{\text {Estimate }}\right)$

\begin{tabular}{ccc}
\hline \hline $\begin{array}{c}\text { Rate of } \\
\text { Depreciation }\end{array}$ & $\lambda^{\text {Estimate }}$ & $\lambda^{\text {Solow }}$ \\
\cline { 1 - 1 } 6 per cent & & \\
& 0.069 & 0.063 \\
& $(0.002)$ & \\
5 per cent & & \\
& 0.063 & 0.056 \\
& $(0.002)$ & \\
4 per cent & & \\
\hline & 0.056 & 0.049 \\
& $(0.002)$ & \\
\hline \hline
\end{tabular}

Note: The sample covers 96 countries over the 41 year period 1960-2000. Estimates are generated over a 5 year interval for the sample. Standard errors are in parenthesis. $\lambda^{\text {Solow }}$ refers to the convergence rate suggested by the Solow model as given by $(1-\alpha)\left(\overline{g_{i}}+\overline{n_{i}}+\delta\right)$. 
Table 2: Convergence Estimates for Smaller Country Samples

\begin{tabular}{|c|c|c|c|}
\hline \multirow{2}{*}{$\begin{array}{c}\text { Rate of } \\
\text { Depreciation }\end{array}$} & \multicolumn{2}{|c|}{$\lambda^{\text {Estimate }}$} & \multirow[b]{2}{*}{$\lambda^{\text {Solow }}$} \\
\hline & Intermediate & OECD & \\
\hline \multirow[t]{2}{*}{6 per cent } & & & \\
\hline & $\begin{array}{c}0.070 \\
(0.002)\end{array}$ & $\begin{array}{c}0.067 \\
(0.003)\end{array}$ & 0.063 \\
\hline \multirow[t]{2}{*}{5 per cent } & & & \\
\hline & $\begin{array}{c}0.064 \\
(0.002)\end{array}$ & $\begin{array}{c}0.060 \\
(0.003)\end{array}$ & 0.056 \\
\hline \multirow[t]{2}{*}{4 per cent } & & & \\
\hline & $\begin{array}{l}0.0573 \\
(0.002)\end{array}$ & $\begin{array}{c}0.053 \\
(0.003)\end{array}$ & 0.049 \\
\hline
\end{tabular}

Note: The "Intermediate" and "OECD" samples refer to sub-samples introduced by Mankiw Romer and Weil (1992). The former consists of 80 countries where the remaining countries (16) have been excluded on the basis of either receiving a grade $\mathrm{D}$ for data quality or their population was less than 1 million in 1960. The OECD sample contains 23 countries. The time period is 19602000 and estimates are again generated over a 5 year interval for the sample. Standard errors are in parenthesis. $\lambda^{\text {Solow }}$ refers to the convergence rate suggested by the Solow model as given by $(1-\alpha)\left(\overline{g_{i}}+\overline{n_{i}}+\delta\right)$. 
Figure 1: Correlation of TFP Levels and Investment Shares

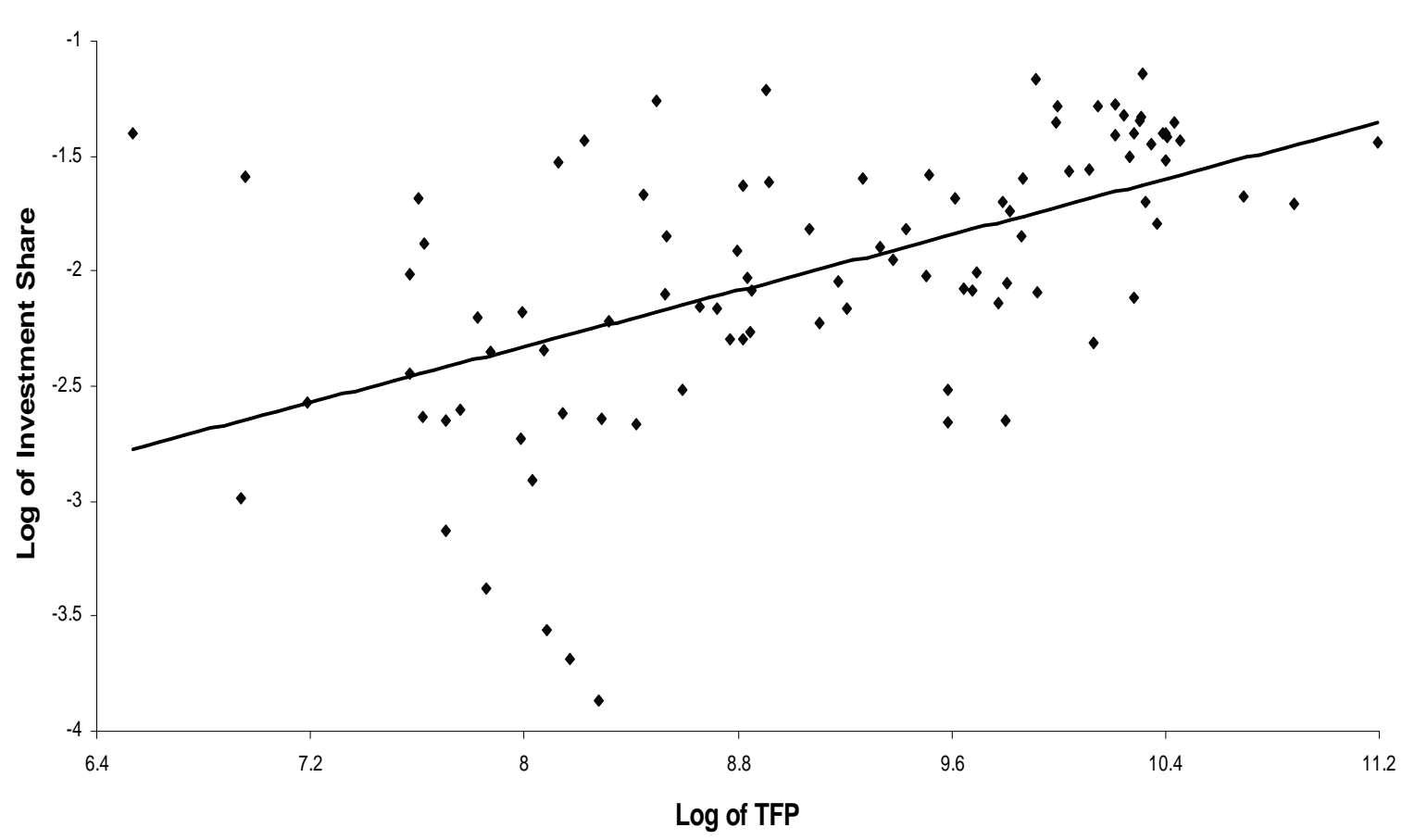


Figure 2: Correlation of TFP Levels and Population Growth

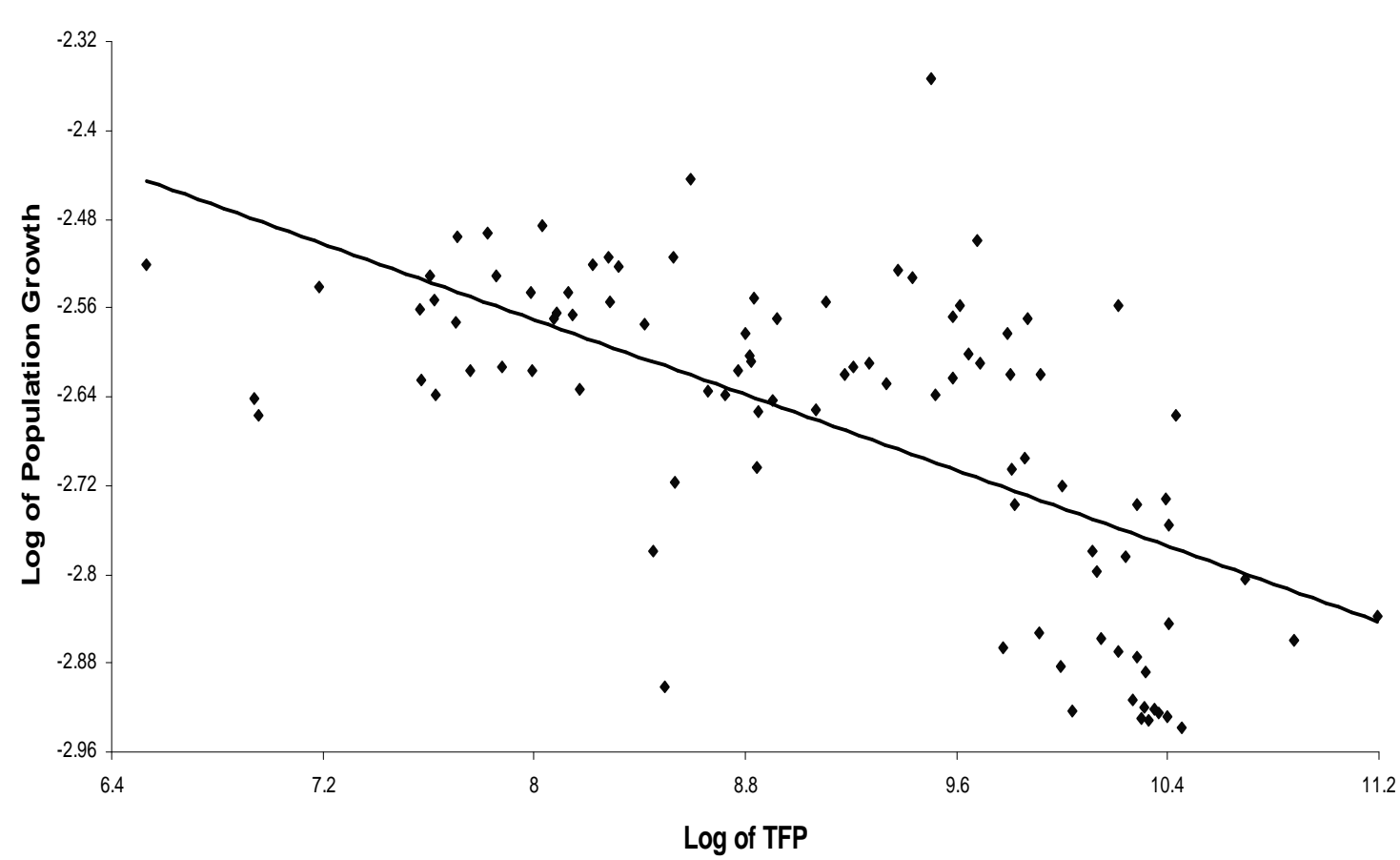


Figure 3: Correlation of Y/L and TFP 1960-2000 Growth Rates

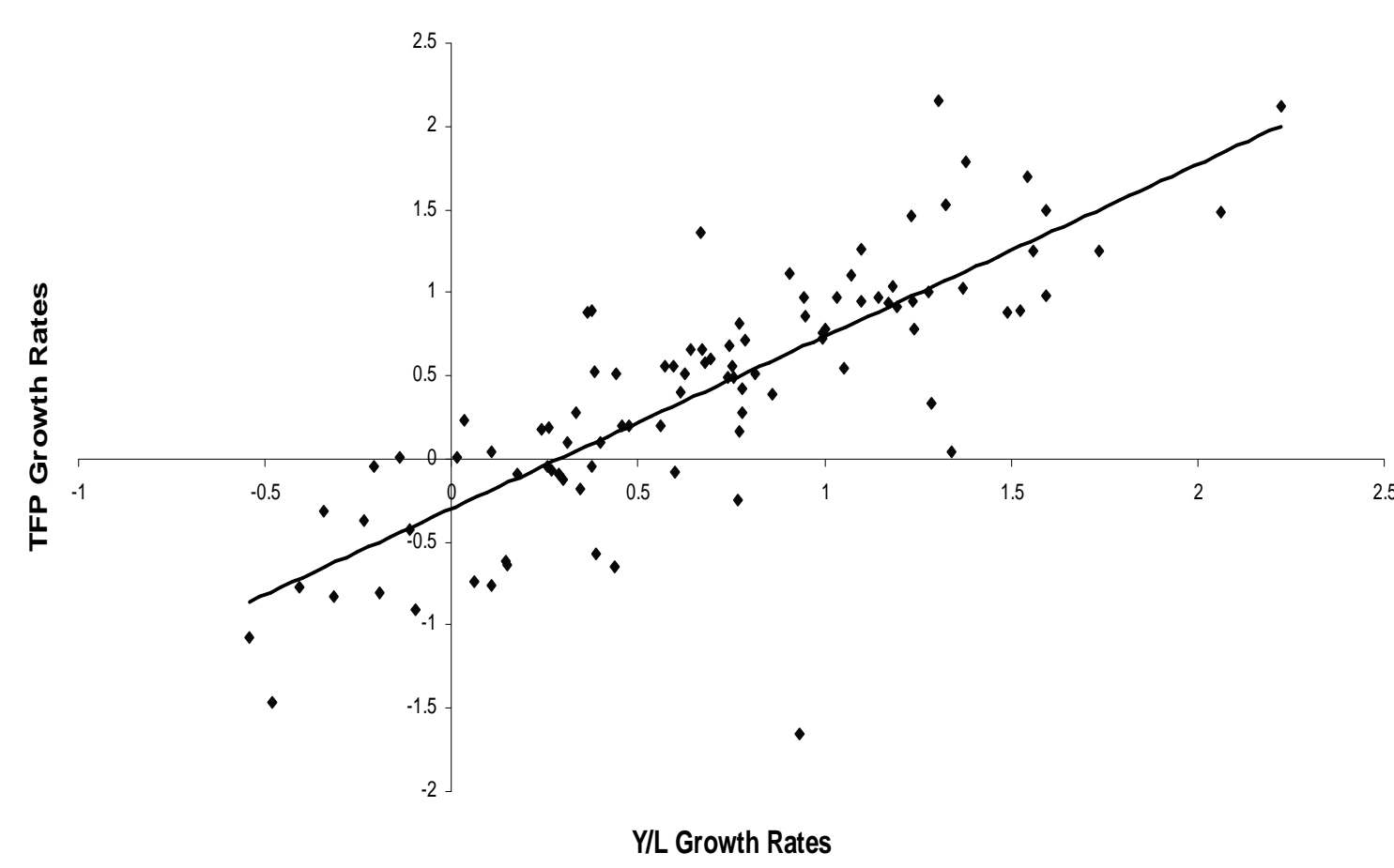


Figure 4: Correlation of Y/L and K/Y 1960-2000 Growth Rates

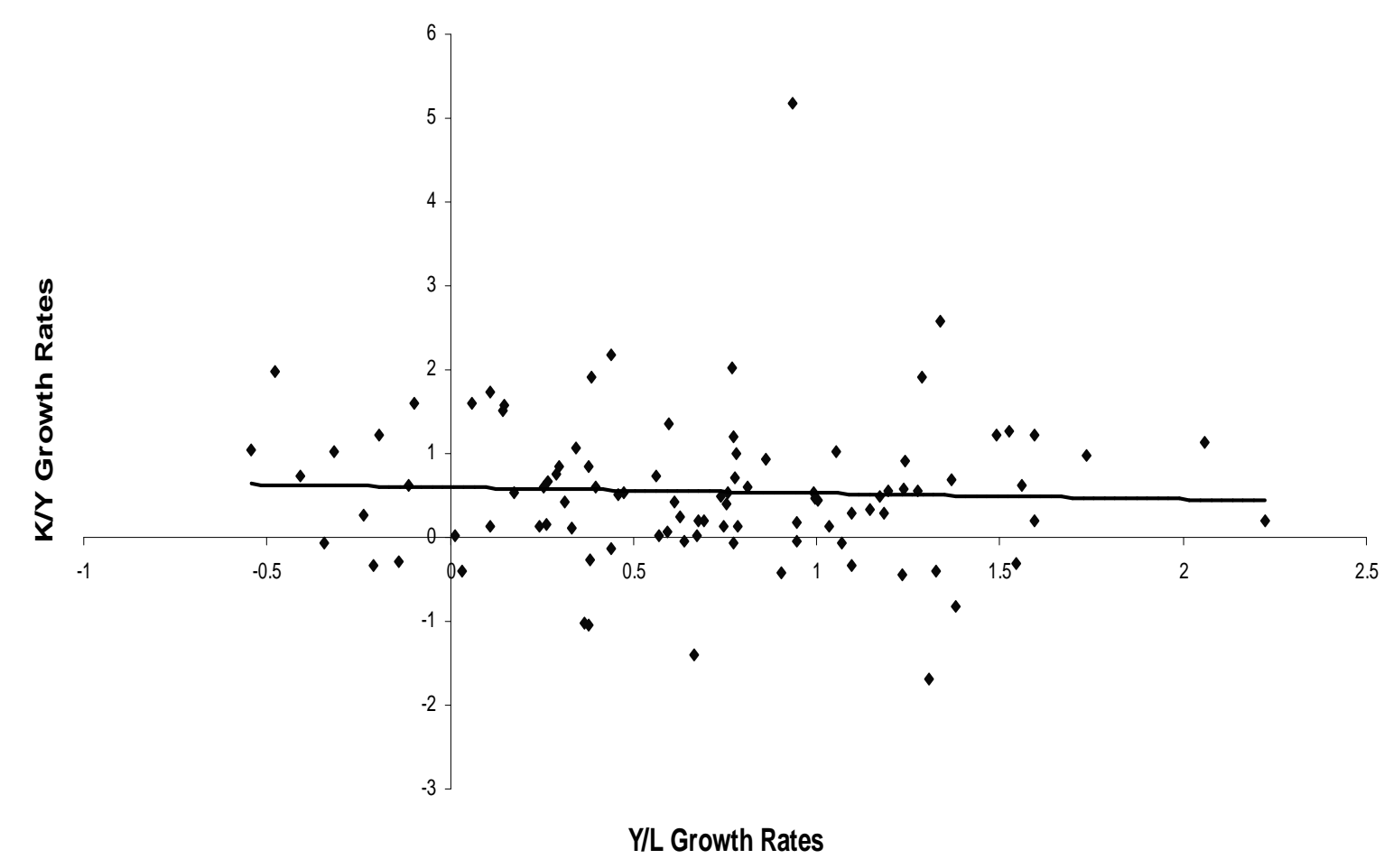

